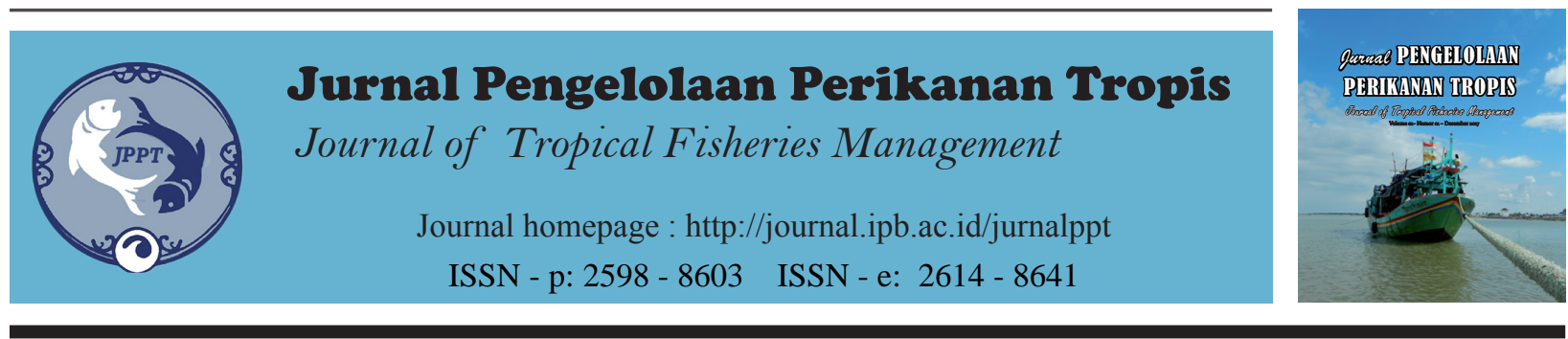

\title{
Kematangan Gonad dan Potensi Reproduksi Ikan Banyar (Rastrelliger kanagurta, Cuvier 1817)
}

\author{
(Gonado Maturity and Reproduction Potential of Indian Mackerel \\ (Rastrelliger kanagurta, Cuvier 1817))
}

\author{
Dian Safarini' ${ }^{1}$, Ali Mashar²
}

\begin{tabular}{l} 
ARTIKEL INFO \\
\hline Article History \\
Received : 20 November 2017 \\
Accepted : 24 Desember 2017 \\
\hline Kata kunci: \\
Banyar, Kematangan gonad, \\
reproduksi, Labuan \\
\hline Korespondensi Author \\
1 Pusat Penelitian Ilmu dan Teknologi \\
(Puspitek), Serpong email: \\
diansafarini@ymail.com \\
2 Departemen Manajemen Sumberdaya \\
Perairan, Fakultas Perikanan dan \\
Ilmu Kelautan, Institut Pertanian \\
Bogor. email: yonvitr@yahoo.com, \\
alimashar75@gmail.com
\end{tabular}

\begin{abstract}
ABSTRAK
Ikan banyar (Rastrelliger kanagurta) merupakan salah satu ikan ekonomis penting dari perairan Teluk Banten. Informasi biologi reproduksi $R$. kanagurta ini masih sedikit sehingga diperlukan kajian reproduksi bagi pengelolaan di masa mendatang. Penelitian dilakukan dari Mei hingga Agustus 2012 melalui pengumpulan sampel dan data di lapangan yang meliputi panjang dan bobot total, tinggi, serta lebar tubuh. Analisis reproduksi, yaitu bobot dan volume gonad, serta diameter telur. Hasil menunjukkan bahwa ikan berukuran 137-257 mm dengan pertumbuhan allometrik negatif di mana pertumbuhan jantan lebih cepat dibandingkan betina. Faktor kondisi R. kanagurta berkisar antara 0,8483-1,1788. Rasio kelamin ikan jantan dengan betina adalah 1,11:1. Ukuran pertama kali matang gonad adalah 220,32 mm untuk betina dan $211.07 \mathrm{~mm}$ untuk jantan. Nilai IKG ikan betina lebih tinggi dibandingkan jantan di mana nilai tertinggi terdapat diakhir Juli yang menunjukkan musim pemijahannya. Ikan ini memiliki tipe pemijahan total spawner dan mengeluarkan \pm 25691 butir telur dalam sekali pemijahan dengan diameter telur ikan berkisar antara $0,05-1,08 \mathrm{~mm}$.
\end{abstract}

\section{PENDAHULUAN}

Ikan banyar ( $R$. kanagurta) merupakan salah satu jenis ikan laut yang bergerombol di permukaan laut pada musim-musim tertentu sehingga mudah sekali tertangkap. Ikan ini merupakan komoditas perikanan penting yang diminati banyak orang untuk dikomsumsi dalam pemenuhan gizi seharihari karena harganya yang murah dan gizinya yang cukup tinggi. Tingginya minat masyarakat terhadap $R$. kanagurta mendorong banyak pelaku perikanan untuk mengeksploitasi sumberdaya ini tanpa memerhatikan keberlanjutan dari kegiatan tersebut. Keberlanjutan kesediaan ikan ditentukan oleh potensi pertumbuhan dan reproduksi ikan tersebut. Eksploitasi yang terus-menerus tanpa memerhatikan keberlanjutannya dapat menyebabkan penurunan kualitas dan kuantitas sumberdaya yang secara tidak langsung dapat menyebabkan kepunahan spesies.

Salah satu perairan yang memiliki sumberdaya ikan banyar adalah perairan Teluk Banten, Provinsi Banten. Tingkat eksploitasi R. kanagurta di Provinsi Banten dapat terlihat dari hasil tangkapan yang terus menurun walaupun upaya penangkapan telah ditingkatkan, produksi R. kanagurta di Kabupaten Pandeglang pada tahun 2000 sebesar 3072,10 ton dengan upaya 12 unit dan terus-menurun hingga tahun 2009 mecapai 1654,30 ton dengan upaya 27 unit (DKP Provinsi Banten 2011). Penurunan populasi R. kanagurta juga dapat disebabkan oleh degradasi kualitas lingkungan pesisir, termasuk pencemaran perairan akibat aktivitas manusia, kegiatan perikanan 
yang merusak, penangkapan ikan berlebih dan dilakukan secara tidak sah, baik oleh pelaku dalam negeri maupun pihak asing di Indonesia. Menurut Mahyuddin (2012), penurunan sumberdaya ikan dapat mengakibatkan Indonesia kesulitan dalam meningkatkan produk secara nyata melalui kegiatan perikanan tangkap.

Kajian $R$. kanagurta di PPN Karangantu, Serang, Provinsi Banten sampai saat ini belum banyak sehingga informasi bagi pengelolaannya masih sangat terbatas. Agar stok R. kanagurta di PPN Karangantu tetap lestari, diperlukan pengelolaan berkelanjutan dari semua aspek, termasuk reproduksinya. Dalam reproduksi ikan, hal yang harus diketahui adalah indeks kematangan Gonad (IKG), tingkat kematangan gonad (TKG), ukuran pertamakalimatang gonad, fekunditas, dan diameter telur. Dengan mengetahui reproduksinya, dapat dibuat kebijakan penangkapan dan pengelolaan berkelanjutan yang akan mempertahankan kualitas dan kuantitas $R$. kanagurta di perairan, khususnya perairan Teluk Banten.

\section{METODOLOGI}

\section{Lokasi Penelitian}

Penelitian dilakukan selama bulan Mei hingga Agustus 2012. Sampel ikan berasal dari Perairan Teluk Banten yang didaratkan di PPN Karangantu, Kabupaten Serang. Analisis reproduksi dilakukan di Laboratorium Biologi Perikanan, Departemen Manajemen Sumberdaya Perairan, Fakultas Perikanan dan Ilmu Kelautan, Institut Pertanian Bogor.

\section{Analisi Data}

Data dikumpulkan dari 700 ikan sampel selama tujuh bulan pengamatan. Data dalam penelitian mengenai ikan banyar ( $R$. kanagurta) ini dikumpulkan secara langsung di lapangan dan di laboratorium. Sampel ikan diambil secara acak sejumlah \pm 100 ekor dalam sekali pengambilan sampel dengan jangka waktu 13 hari. Pengukuran dilapangan meliputi pengukur panjang total menggunakan penggaris dan penimbangan bobot tubuh menggunakan timbangan analog.

Proses pengumpulan data di laboratorium adalah penentuan TKG berdasarkan King (2007) untuk betina dan Effendie (2002) untuk jantan. Penentuan TKG dilakukan secara visual berdasarkan bentuk morfologi gonad.

Selanjutnya, ditentukan volume gonad total (gr). Sementara untuk mendapatkan data fekunditas, diambil contoh dari bagian anterior, middle, posterior. Gonad contoh kemudian dipilih sebagai sampel untuk menentukan diameter telur.

Analisis indeks kematangan gonad dilakukan untuk mengetahui puncak pemijahan dengan formula berikut (King 2007):

$$
I K G=\frac{B G}{B T} \times 100 \%
$$

IKG adalah indeks kematangan gonad; BG adalah berat gonad total (gram); dan BT adalah berat tubuh (gram). Semakin tinggi indeks gonad, peluang ikan menunjukkan kondisi ikan yang kematangan gonadnya semakin berkembang.

Penentuan fekunditas dilakukan menggunakan metode gabungan dengan diawali pengenceran $10 \mathrm{ml}$ pada tiap bagian gonad. Nilai fekunditas ditentukan dari jumlah telur dalam $1 \mathrm{ml}$ contoh. Analisis fekunditas menurut Effendie (2002) dapat dilakukan dengan:

$$
F=\frac{G \times \mathrm{V} \times \mathrm{X}}{Q}
$$

$\mathrm{F}$ adalah fekunditas (butir); $\mathrm{X}$ adalah jumlah telur dalam $1 \mathrm{ml} ; \mathrm{G}$ adalah berat gonad total; $\mathrm{Q}$ adalah berat gonad contoh; dan $\mathrm{V}$ adalah Volume pengenceran $(10 \mathrm{ml})$.

Untuk melihat pengaruh panjang terhadap fekunditas, dilakukan analisis prediksi dengan fungsi polynomial:

$$
F=a+b X+c X^{2}
$$

$\mathrm{F}$ adalah fekunditas (butir); a,b,c adalah konstanta hasil regresi; dan $\mathrm{X}$ adalah Panjang total (mm).

Pengukuran diameter menggunakan mikroskop dengan mikrometer yang telah ditera. Telur yang diukur diameternya sebanyak 50 butir dari setiap bagian pada gonad TKG 3 dan TKG 4 . Selanjutnya, telur diukur di bawah mikroskop dengan metode penyapuan menggunakan perbesaran $4 \times 10$. Data diameter telur yang telah diperoleh dikonversi dengan dikalikan nilai konversi 0,025 . Selanjutnya, dicari jumlah kelas dan dibuat selang kelas dari hasil konversi, kemudian frekuensi pada tiap selang kelas. Persentase diameter telur per selang kelas panjang menurut Effendie (2002) adalah:

$$
P=\frac{m_{i}}{M_{j}} x 100 \%
$$

$\mathrm{P}$ adalah Persentase diameter telur per selang kelas panjang; mi adalah frekuensi ikan pada selang kelas ke-i; dan Mi adalah jumlah ikan TKG ke-j 


\section{HASIL DAN PEMBAHASAN}

\section{Tingkat Kematangan Gonad}

Selama penelitian didapatkan ikan banyar sebanyak 714 ekor di mana terdapat 338 ekor ikan betina dan 376 ekor ikan jantan. Kondisi ini hampir sama rasion $R$. kanagurta dari Southwest coast of India di mana jumlah jantan juga lebih dominan (Ravichandran et al. 2009) Tingkat kematangan gonad $R$. kanagurta di Teluk Banten bervariasi selama periode pengambilan sampel. Tabel 1 menampilkan jumlah ikan pada jenisnya masing-masing terhadap TKG. Tabel 1 juga menunjukkan bahwa ikan betina memiliki jumlah yang lebih banyak pada TKG 1, 2, dan 4. Namun pada TKG 3 dan 4, ikan jantan memiliki jumlah yang lebih banyak dibandingkan betina pada TKG yang sama. Secara keseluruhan, rasio ikan betina dan ikan jantan dari seluruh TKG, yaitu 1:1,1 di mana ikan jantan lebih banyak. Ikan betina mencapai $47,33 \%$ dan ikan jantan 52,66\%. Penelitian di perairan Kuantan komposisi jantan juga lebih besar $(57,75 \%)$ dan betina $(42,25 \%)$ (Rahman dan Hafzath 2012), dan di Teluk Suez
Jantan (51\%) dan betina (49\%) (Mahenna 2001) Gambar 1 menunjukkan $R$. kanagurta betina sudah terdapat TKG 4 dan 5 pada selang 170$180 \mathrm{~mm}$ yang lebih kecil dari $R$. kanagurta dari Ratnagiri coast, yaitu $198 \mathrm{~mm}$ (Bhendarkar et al. 2013). Pada ikan jantan, telah terdapat TKG 3, 4, dan 5 pada selang $159-169 \mathrm{~mm}$ yang juga lebih rendah dari Ratnagiri Coast (Bhendarkar et al. 2013), yaitu $206 \mathrm{~mm}$ namun lebih tinggi dari yang di Calicut, yaitu $150 \mathrm{~mm}$ (Sivadas et al. 2006). Gambar 1 juga menunjukkan hanya terdapat ikan TKG 4 pada ikan betina ukuran 225-235 mm dan 247-257 mm untuk ikan jantan yang juga lebih tinggi Calicut, yaitu 155 $\mathrm{mm}$ (Sivadas et al. 2006). Hubungan panjang dengan TKG dapat dilihat pada Gambar 2 yang menunjukkan bahwa pada $R$. kanagurta jantan maupun betina mengalami peningkatan rata-rata panjang sejalan pertambahan TKG. Peningkatan rata-rata panjang terjadi pada TKG 1 hingga 4, namun rata-rata panjang lebih kecil terdapat pada ikan dengan TKG 5. Hubungan panjang dengan tingkat kematangan gonad pada ikan banyar tidak jauh berbeda pada masing-masing kelamin. Pada
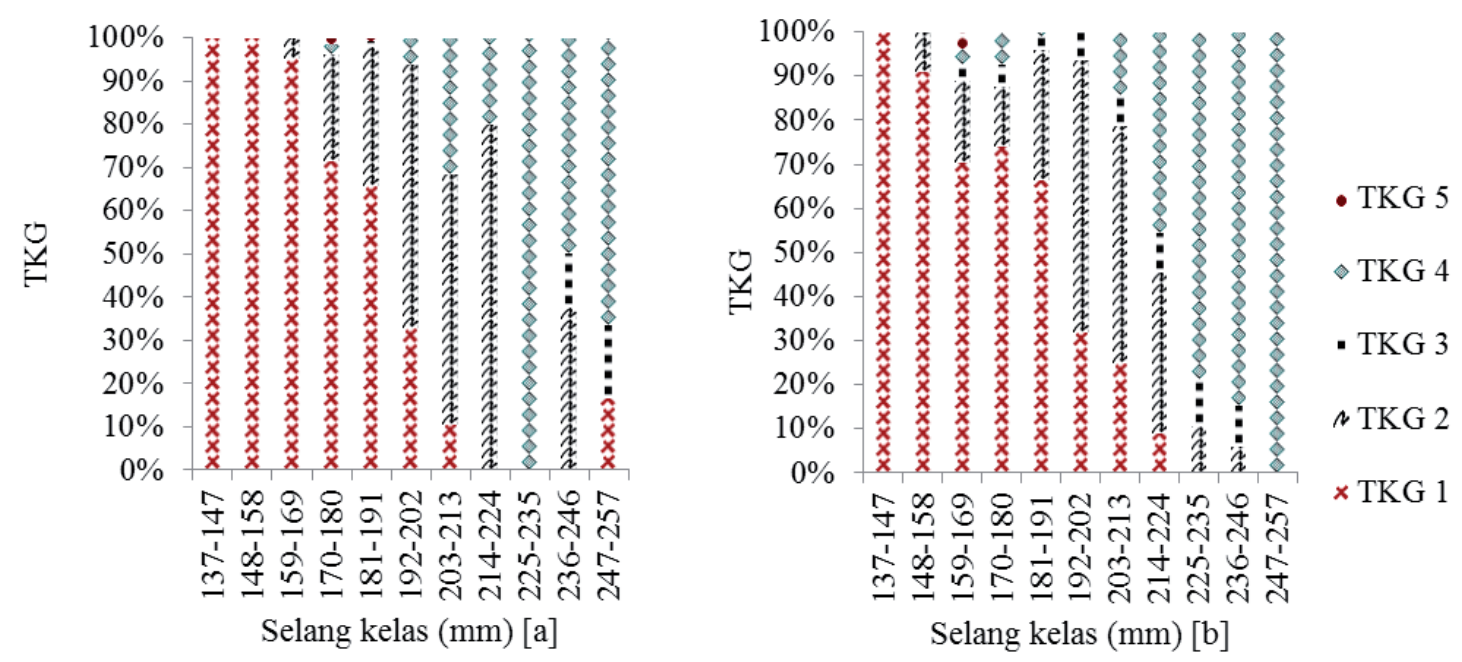

Gambar 1 TKG ikan banyar dari perairan Teluk Banten

Tabel 1 Tingkat kematangan gonad ikan banyar

\begin{tabular}{|c|r|r|r|r|r|r|}
\hline TKG & Betina & Jantan & \multicolumn{1}{c|}{ Total } & \multicolumn{1}{c|}{ Rasio } & \multicolumn{1}{c|}{ Xhit } & \multicolumn{1}{c|}{ Xtab } \\
\hline 1 & 199 & 188 & 387 & $1,06: 1$ & 0,3127 & 12,7062 \\
\hline 2 & 111 & 99 & 210 & $1,12: 1$ & 0,5769 & \\
\hline 3 & 4 & 20 & 24 & $1: 5$ & 9 & \\
\hline 4 & 22 & 68 & 90 & $1: 3,09$ & $23,5111^{*}$ & \\
\hline 5 & 2 & 1 & 3 & $2: 1$ & 0,3333 \\
\hline Jumlah & 338 & 376 & 714 & $1: 1,1$ & & \\
\hline
\end{tabular}

*) Signifikan pada selang kepercayaan 95\% 
R. kanagurta, baik betina maupun jantan, rata-rata panjang meningkat dari TKG 1 hingga TKG 4, namun rata-rata panjang pada ikan TKG 5 tidak jauh berbeda dengan ikan TKG 1. Hal ini dapat disebabkan keberadaaan makanan, laju hormon gonadotropin yang memengaruhi waktu matang gonad, faktor genetik dan kemungkinan terdapat ikan yang telah memijah pada ukuran lebih kecil.

\section{Indeks Kematangan gonad}

Indeks kematangan gonad ikan banyar betina secara umum lebih besar dibandingkan ikan jantan dengan peningkatan nilai IKG sejak mencapai TKG 3 dan meningkat tajam pada TKG 4. IKG ikan betina berkisar antara 0,1188-3,7274, sedangkan ikan jantan antara 0,1232-1,6163. Hasil penelitian menunjukkan bahwa IKG ikan banyar meningkat sejalan dengan peningkatan TKG.

Ikan banyar dari perairan Teluk Banten memiliki nilai IKG tertinggi pada pengambilan sampel ke-5, yaitu tanggal 26 juli 2012 dan terendah pada sampel ke-3, yaitu tanggal 30 Juni 2012. Tingginya nilai IKG pada sampel ke-5 menunjukkan bahwa ikan banyar di Teluk Banten mengalami puncak pemijahan pada bulan tersebut. Hal ini tidak jauh berbeda dengan pernyataan Sudjastani (1974) bahwa pemijahan ikan banyar terjadi antara Oktober hingga Februari pada musim barat dan Juni hingga September pada musim timur. Perairan Kuantan puncak IKG juga terjadi pada bulan Februari sampai Mei (Rahman dan Hafzath 2012) dan di Pesisir Ratnagiri India terjadi perubahan dari bulan Maret-Mei (Sekharan 1958; Gopakumar 1991; Abdussamad et al. 2010) menjadi Juni-September (Bhendarkar et al. 2013). Nilai IKG juga merupakan salah satu indikator dari "spawning frequency" ikan (Webb dan Feist 2002).

Gambar 5 menampilkan hubungan panjang TKG untuk IKG 0,0019-0,6854 dan 0,69541,3789. Sama dengan ikan demersal dari kelas Siluriformes bahwa IKG ikan betina lebih tinggi dari ikan jantan (Duarte et al. 2007) Pada Gambar 5a, diketahui terdapat penambahan panjang selama perubahan TKG 1-3, namun menurun ketika TKG 4 dan kembali ke ukuran sebelumnya pada TKG 5 yang menandakan perbedaan yang tidak jauh berbeda antara TKG 3-5. Berbeda dengan Gambar 5b yang memiliki peningkatan panjang hanya ketika perubahan TKG 1-2 dan menurun ketika menjadi TKG 3-4. Hal ini dapat disebabkan kurangnya sampel ikan dengan kisaran IKG tersebut. Namun, jika dilihat dari struktur keseluruhan dan selang kelas yang ada diketahui bahwa pertumbuhan TKG sejalan dengan pertumbuhan panjang.

\section{Fekunditas}

Ikan banyar yang berasal dari perairan Teluk Banten mengeluarkan 9.058-55.181 butir telur dengan rata-rata \pm 25.690 butir setiap kali pemijahan yang tidak jauh berbeda dengan R. kanagurta di Teluk Thailand dengan \pm 20.000 butir telur setiap pemijahan (Boonprakop 1966 in Sudjastani 1974). Berdasarkan Tabel 2, diketahui $R$. kanagurta dengan TKG 3 hanya 4 ekor yang berada pada selang ukuran 170-190 mm, 231-230 mm dan 251-270 mm dengan fekunditas rata-rata $9829.92-17 \quad 835.74$ butir tergolong rendah dari $R$. kanagurta dari Ratnagiri coast berkisar antara 55.265-314.568 butir (Bhendarkar et al. 2013). Ikan dengan TKG 4 terdapat pada tiap selang ukuran dengan fekunditas rata-rata 10.270,38-31.046,69 butir. Hubungan panjang dengan fekunditas ikan banyar dinyatakan dalam persamaan polinomial, yaitu $\mathrm{F}=-10.2147 \times 2$ $+4615.3971 \mathrm{x}-487670.9963$ yang berarti fekunditas tertinggi dialami ikan ketika mencapai panjang 225,919 mm. Ukuran kematangan ini lebih rendah dari rata-rata tangkapan komersial dari laut Oman, yaitu $253 \mathrm{~mm}$ (Jawad et al. 2011) dan hampir sama dengan $R$. kanagurta dari Cochin (George dan Banerji (1967) yang dapat mencapai $77 \mathrm{~mm}$. Gambar 6 menunjukkan bahwa peningkatan fekunditas ikan banyar secara umum sejalan dengan peningkatan ukuran panjang.

\section{Diameter telur}

Ikan banyar yang didapatkan dari perairan Teluk Banten selama periode Mei hingga Agustus 2012 didapatkan 26 ekor ikan betina yang telah mencapai TKG 3 dan 4. Ikan banyar betina dengan TKG III dan IV yang ada di perairan Teluk Banten memiliki diameter telur yang berkisar antara 0,05-1,08 mm (Gambar 5). Diameter telur dengan frekuensi tertinggi terdapat pada selang kelas 0,21-0,28 mm. Dari sebaran diameter telur terdapat satu puncak yangmenunjukkan bahwa R. kanagurta termasuk ke dalam kelompok ikan total spawner yang berarti ikan memijah tidak bertahap di mana ikan memijah secara menyeluruh (Effendie 2002). R. kanagurta dari Ratnagiri coast juga berpola total spawner (one a year) (Bhendarkar et al. 2013).

Penelitian menunjukkan terdapat hubungan antara berat gonad total (BGT) dengan diameter telur, semakin besar nilai BGT maka semakin besar pula diameter telurnya. Hubungan antara berat 
Tabel 2 Jumlah, panjang, dan fekunditas ikan banyar pada TKG 3 dan 4

\begin{tabular}{|c|c|c|c|c|c|}
\hline \multirow{2}{*}{ TKG } & \multicolumn{5}{|c|}{ Selang Kelas Panjang (mm) } \\
\hline & 170-190 & $191-210$ & $211-230$ & $231-250$ & $251-270$ \\
\hline \multicolumn{6}{|c|}{ TKG 3} \\
\hline Total (ekor) & 2 & 0 & 0 & 1 & 1 \\
\hline Rataan panjang & 182 & - & - & 237 & 255 \\
\hline \multirow[t]{2}{*}{ Fekunditas } & $9.829,92$ & - & - & $9.704,27$ & $17.835,74$ \\
\hline & \multicolumn{5}{|c|}{ TKG 4} \\
\hline Total (ekor) & 2 & 9 & 2 & 6 & 3 \\
\hline Rataan panjang & 179,5 & 203,33 & 222 & 240 & 255,67 \\
\hline Fekunditas & $10.270,38$ & $29.748,88$ & $39.194,37$ & $26.822,14$ & $31.046,69$ \\
\hline
\end{tabular}

gonad ikan dengan diameter telur R.kanagurta dinyatakan dengan $\mathrm{y}=0,2361 \times 0,2926$ di mana koefisien determinasinya (R2) adalah 0,7515 . Dari hubungan BGT dengan diameter telur didapatkan bahwa R.kanagurta memiliki diameter telur ratarata terbesar ketika $\mathrm{BGT}=8,2377$ gram dengan nilai $0,4940 \mathrm{~mm}$.

\section{KESIMPULAN}

Berdasarkan penelitian selama bulan Mei hingga Agustus 2012, didapatkan bahwa ikan banyar mengalami peningkatan tingkat kematangan gonad sejalan dengan peningkatan ukuran panjang. Puncak pemijahan ikan banyar dari Teluk Banten adalah pada akhir Juli dengan pola pemijahan tidak bertahap (total spawner) dan mengeluarkan \pm 25.690 butir telur dalam sekali pemijahan.

\section{DAFTAR PUSTAKA}

Abdussamad EM, Pillai NGK, Kasim MH, Mohamed OMMJ, Jayabalan K. 2010. Fishery biology and population characteristics of the Indian mackerel, RastrelligeR kanagurta (Cuvier) exploited along Tuticorin Coast. Indian $J$ Fish 57: $17-21$

Adi NS, Rustam A. 2010. Studi awal pengukuran sistem $\mathrm{CO}_{2}$ di Teluk Banten In: Prosiding Pertemuan Ilmiah TahunanIV. Ikatan Sarjana Oseanologi Indonesia 2010[Internet]. [Waktu dan tempat pertemuan tidak diketahui]. Bogor (ID) : LPSDKP. [Diunduh 2012 Desember 27]. Tersedia pada : http:// www.lpsdkp.litbang.kkp.go.id/index.php/ prosiding?download $=9 \% 3$ Astudi-awalpengukuran-sistem-co2-di-teluk-banten.pdf.

Bhendarkar MP, Naik SD, Mohite SA, Kulkarni GN. 2013. Reproduktive Biology of Indian Mackerel, Rastrelliger kanagurta (Cuvier
1817) of Ratnagiri Coast, Maharashtra, India. Discovery Science 3(9): 24-26.

[DKP] Dinas Kelautan dan Perikanan Provinsi Banten. 2011. Statistik Perikanan Daerah Banten Tahun 2000-2009. Serang (ID): DKP Banten.

Duarte1 S, FG Araújo1, A Sales and N Bazzoli3. 2007. Morphology of gonads, Maturity and Spawning Season of Loricariichthys spixii (Siluriformes, Loricariidae) in a Subtropical Reservoir. Brazilian Archives of Biology and Technology 50(6):1019-1032.

Effendie MI. 2002. Biologi Perikanan. Yogyakarta (ID): Yayasan Pustaka Nusantara.

George KC, SK Banerji. 1967. Age and Growth studies on the Indian Mackerel (Rastrelliger kanagurta (Cuvier 1817) with special reference to length-frequency data colleted at Cochin. Indian Journal of Fisheries 16(3): 621-638.

Jawad LA, A Ambuali, JM Al Mamry, HK Al Busaidi. 2011. Relationship between fish length and Otolith Length, width and Weight of the Indian Mackerel (Rastrelliger kanagurta, Cuvier 1817) collected from the Sea of Oman. Rihabrstvo 69(2): 51-61.

King MG. 2007. Fisheries Biology Assessment and Management. Second edition. United Kingdom (UK): Blackwell Publishing Ltd.

Mahyuddin B. 2012. Kebutuhan teknologi untuk pengembangan penangkapan ikan In: Pengelolaan Sumberdaya Kelautan berbasis IPTEKS untuk Kemakmuran Bangsa. Seminar Nasional Kelautan VIII [Internet]; 2012 Mei 24; Surabaya, Indonesia. Bogor (ID): BBPPI. [diunduh 2012 Desember 2012]. Tersedia pada : http://bbppi.info/ files/Makalah-KaBalai.pdf.

Mehanna SF. 2001. Dynamic and Management of Indian Mackerel RastelligeR kanagurta (Cuvier 1816) in the Gulf of Suez, Egypt. 
Ravichandran S. G Rameshkumar, B Mahesh, and Egypt. J. Aquat. Biol. \& Fish.,Voi5, No. 3 :179 - 194 (2001) K Mukaravel. 2009. Infestation of Rastrelliger kanagurta, with Cymothoid Isopod, Joryma brachysoma in the colachel environment of Southwest Coast of Indian. World Journal of Fish and Marine Sciences 1(2): 80-84 IDOSI Publications.

Rahman MM, A Hafzath 2012. Condition. Length-Weght Relationship, sex ration and Gonadosomatic Index of Indian Mackerel (Rastrelliger kanagurta) captured from Kuantan Coastal Water. Journal of Biological Science. DOI. 10.3923. 1-7. Asian Network for Scientific Information.
Sudjastani T. 1974. The Species of Rastrelliger in Java Sea, their taxonomy, morphometry and population dynamics [tesis]. Colombia (CO) :University of British Columbia.

Sivadas M, PNR Nair, KK Balasubramanian, MM Baskaran. 2006. Length weight relationship, relative condition, size at first maturity and sex ratio of Indian mackerel Rastrelliger kanagurta from Calicut. J Mar Biol Ass India 48(2): 274-277 Juli-Desember 2006.

Webb MAH and G Feist. 2002. Potential Classification of Sex and Stage of Gonadal Maturity of Wild White Sturgeon Using Blood Plasma indicatorsTransactions of the American Fisheries Society 131: 132-142. 